\title{
Preliminary study on decreasing the expression of FOXP3 with miR-155 to inhibit diffuse large B-cell lymphoma
}

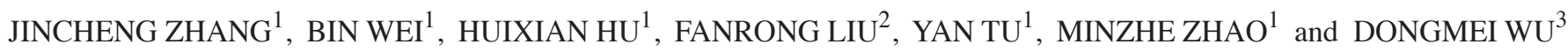 \\ ${ }^{1}$ Department of Hematology, Jinhua Hospital of Zhejiang University, Jinhua, Zhejiang 321000; \\ ${ }^{2}$ Department of Pathology, Second Hospital Affiliated to Nanchang University, Nanchang, Jiangxi 330006; \\ ${ }^{3}$ Department of Pathology, Huashan Hospital Affiliated to Fudan University, Shanghai 201100, P.R. China
}

Received September 21, 2015; Accepted March 30, 2017

DOI: $10.3892 / \mathrm{ol} .2017 .6345$

\begin{abstract}
The aim of the present study was to analyze the association between the transcription factor forkhead box P3 (FOXP3) and diffuse large B-cell lymphoma (DLBCL), and investigate the effect of microRNA-155 (miR-155) on the generation and development of FOXP3 in DLBCL. The reverse transcription-quantitative polymerase chain reaction (RT-qPCR) technique was used to determine the expression of FOXP3 in the human DLBCL cell lines Ly1, Ly8 and Ly10, and in normal B cells. An immunohistochemical method was used to determine FOXP3 expression in 60 DLBCL tumor and adjacent tissues, and a retrospective analysis of FOXP3 expression in tumor tissues and clinical data was performed. The lentiviral transfection technique was used to silence the miR-155 gene in mouse A20 cells to analyze the influence of miR-155 on FOXP3 in DLBCL. The A20 cell line with a silenced miR-155 gene was used to perform a tumorigenicity assay in $\mathrm{BALB} / \mathrm{c}$ mice, and to compare the tumorigenicity rate and the tumor growth rate. The results identified that the expression of the transcription factor FOXP3 in the human DLBCL cell lines was increased compared with normal B cells; FOXP3 in human DLBCL tumor issues was increased compared with the tumor-adjacent tissue, and the increased expression of FOXP3 was identified as an indicator of poor prognosis of patients with DLBCL in the middle and late period; FOXP3 level decreased subsequent to silencing miR-155 in A20 cells; A20 cells with the low-expression miR-155 gene were used to determine the tumorigenicity in BALB/c mice and it was identified that the tumorigenicity of the low-expression miR-155 gene group was decreased compared with the untransfected group. Therefore, miR-155 may be a regulatory factor of FOXP3, and miR-155
\end{abstract}

Correspondence to: Mrs. Huixian Hu, Department of Hematology, Jinhua Hospital of Zhejiang University, 351 Mingyue Road, Jinhua, Zhejiang 321000, P.R. China

E-mail: 13588652288@139.com

Key words: microRNA-155, transcription factor, forkhead box P3, diffuse large B-cell lymphoma may be associated with the metastasis and prognosis of patients with DLBCL.

\section{Introduction}

Diffuse large B-cell lymphoma (DLBCL) is the most common type of lymphoma worldwide, accounting for between 40 and $45 \%$ of non-Hodgkin's lymphoma, and its morbidity increases at an annual rate of 3\% (1). Forkhead box P3 (FOXP3) is a transcription factor that is specifically expressed by $\mathrm{T}$ cells. FOXP3 is a marker of regulatory T cells (Tregs) and serves an important role in maintaining the immunosuppressive function of Tregs (2). In the immune system, T cells are responsible for negative regulation and inhibit the proliferation and immunocompetence of immunological effector cells to assist with the formation of autoimmune tolerance (3). $\mathrm{CD} 4^{+} \mathrm{CD} 25^{+} \mathrm{T}$ cells are a principal type of Treg and exhibit an immunosuppressive function (4). Previously, it was identified that $\mathrm{CD} 4^{+} \mathrm{CD} 25^{+}$ $T$ cells exhibit a marked association with certain physiological processes, including autoimmune disease, tumorigenesis, tolerance and anaphylaxis (5). FOXP3 is the basic transcription factor that is essential for differentiation of Tregs, and is therefore a selection marker for Tregs (6) and their defining feature (7). A previous study has identified that the immunosuppressive function of the T cells may be regulated, and the antineoplastic immune response ability of the body may be enhanced, by decreasing the expression of FOXP3 (8). The increased expression of FOXP3 in the majority of tumors is a marker of poor prognosis of patients with cancer (9-11). However, the association between FOXP3 and the prognosis of patients with DLBCL remains unclear.

MicroRNA (miRNA) is a type of non-coding RNA, typically 22 nucleotides in length. A mature miRNA is able to degrade a target signal to inhibit the transcription of RNA and lead to the regulation of target gene expression (12). Previous studies have identified the influence of miRNA on T cells: Studies in animals have suggested that the lack of miRNA results in a deceased number of $\mathrm{T}$ cells in the thymus, spleen and lymph gland $(13,14)$. It has also been identified that FOXP3 may influence the expression of certain miRNAs in T cells; a FOXP3-binding site was identified in specific parts of the miRNA coding area, and FOXP3 may directly or indirectly regulate the expression of certain miRNAs in T cells (15). 
FOXP3 is the basic transcription factor of $\mathrm{T}$ cells. The immunosuppressive function of $\mathrm{T}$ cells weakens the antineoplastic immune response ability of the body. However, to the best of our knowledge, previous studies have rarely investigated the regulation of FOXP3 expression. miR-155 is a modulator of FOXO3a protein has been identified as a potential regulator of FOXP3 (16). It was hypothesized that miR-155 may influence the expression of FOXP3 and exhibit an interference effect on the progression of DLBCL. Therefore, to determine the role of FOXP3 in DLBCL, the expression of FOXP3 was investigated in the human DLBCL cell lines Ly1, Ly8 and Ly10, the mouse DLBCL cell line A20, and normal B cells, and the expression of FOXP3 in DLBCL tumor tumor-adjacent tissues was compared in order to analyze the association between the expression of FOXP3 in the tumor tissues and prognosis. The lentiviral transfection technique was used to silence the miR-155 gene in the A20 cells in order to analyze the effect of the miR-155 gene on FOXP3 in DLBCL. The A20 cell line, following stable transfection, was used in a tumorigenicity experiment in BALB/c mice to compare the tumorigenicity and tumor growth rates, and provide evidence to support the hypothesis that decreasing the expression of FOXP3 by miR-155 inhibits DLBCL.

\section{Materials and methods}

Materials. A total of 60 male BALB/c mice (6-week-old; weight, $25 \pm 5 \mathrm{~g}$ ) were purchased from the Central Laboratory of Animal Science of the Zhejiang University Medical College (Jinhua, China). All animals received humane care according to the criteria outlined in the 'Guide for Care and Use of Laboratory Animals' (17). The animal protocol was approved by the Animal Care and Use Committee of Zhejiang University Medical College.

Normal B cells, the human DLBCL cell lines Ly1, Ly8 and Ly10, and the BALB/c mouse-derived DLBCL A20 cell line were kindly provided by Professor Zhao Tong (Nanfang Hospital, Southern Medical University, Guangzhou, China). A total of 60 surgical resection samples of human DLBCL (including from 42 males and 18 females, with a mean age of 62 years) were obtained from the Department of Pathology of Jinhua Hospital of Zhejiang University (Jinhua, China) between March 2009 to December 2013. Written informed consent was obtained from all patients for the use of their samples.

Reverse transcription-quantitative polymerase chain reaction (RT-qPCR). Total RNA from cells was extracted using TRIzol reagent (Invitrogen; Thermo Fisher Scientific, Inc., Waltham, MA, USA), according to the manufacturer's protocol. cDNA synthesis was performed on 10 ng total RNA using a RevertAid First Strand cDNA Synthesis kit (Thermo Fisher Scientific, Inc.), according to the manufacturer's protocol. RT-qPCR was performed on a 7500/7500 Fast Real-Time PCR system (Applied Biosystems; Thermo Fisher Scientific, Inc.) using a SYBR-Green Premix Ex Taq ${ }^{\mathrm{TM}}$ kit (Takara Bio, Inc., Otsu, Japan). Primer sequences used for the amplification are listed in Table I. A total of 4 replicates were used for each sample. The thermocycling conditions were DNA deformation and polymerase activation at $95^{\circ} \mathrm{C}$ for $3 \mathrm{~min}$, then 38 cycles of denaturation at $95^{\circ} \mathrm{C}$ for $15 \mathrm{sec}$, and amplification and fluorescence measurement at $57^{\circ} \mathrm{C}$ for $60 \mathrm{sec}$. Melting curve analysis was performed between 55 and $95^{\circ} \mathrm{C}$ with increments of $0.5^{\circ} \mathrm{C}$ every $3 \mathrm{sec}$. The relative quantification was determined from $\mathrm{C}_{\mathrm{q}}$ values for each target gene and the internal control gene $(\beta$-actin) in the cell lines, as previously described using GeNorm software (version 3.4) (18).

Immunohistochemistry. Whole sections of human DLBCL samples were sectioned at $0.3 \mu \mathrm{m}$ thickness, deparaffinized in xylene and rehydrated in graduate series of alcohols. Slides were pretreated with $10 \mathrm{mmol} / \mathrm{l}$ citrate buffer ( $\mathrm{pH}$ 6.0) (Thermo Fisher Scientific, Inc.) and stained with a rabbit polyclonal immunoglobulin G anti-FOXP3 antibody (dilution, 1:100; cat. no. ab54501; Dako; Agilent Technologies, Inc., Santa Clara, USA). Briefly, paraffin sections were dewaxed with xylene, soaked for $5 \mathrm{~min}$ in $100 \%$ ethanol and then soaked for $10 \mathrm{~min}$ in $95 \%$ alcohol at room temperature. Antigen retrieval was performed by heating the samples in Dako REAL Target Retrieval solution (Agilent Technologies GmbH, Waldbronn, Germany) for $40 \mathrm{~min}$ at $98^{\circ} \mathrm{C}$. The sections were then treated with $\mathrm{H}_{2} \mathrm{O}_{2}$ to block endogenous peroxidase activity. The sections were then incubated with diaminobenzidine (DAB) substrate (Dako; Agilent Technologies, Inc.) and counterstained with hematoxylin. Image analysis with an optical microscope (magnification, x200; Olympus Corporation, Tokyo, Japan) was performed to determine the average integral optical density of the positive cells using ImagePro Plus software (Image-Pro Plus version 6.0; Media Cybernetics, Rockville, MD, USA) (19). In order to analyze the association between the expression of FOXP3 and the clinicopathological features of patients with DLBCL, Cox's regression model was used to conduct multifactor analysis of the age, expression of FOXP3 within and around tumors, extra-nodal involvement and International Prognostic Index rating clinical stages of patients with DLBCL.

Cell transduction. Human embryonic kidney 293T cells (HEK293T) cells were maintained in Dulbecco's modified Eagle's medium (DMEM; Beijing Solarbio Science \& Technology Co., Ltd., Beijing, China) supplemented with $10 \%$ FBS. The murine leukemia cell line A20 (B lymphocytic) was cultured in RPMI-1640 medium (Beijing Solarbio Science \& Technology Co., Ltd.) supplemented with $10 \%$ FBS and $0.05 \mathrm{mM}$ 2-mercaptoethanol. pLKO-TRC short hairpin RNA (shRNA) clones (cat. nos. TRCN0000068102, TRCN0000068101, TRCN0000068100, TRCN0000068099 and TRCN0000068098) targeting mouse miR-155 were purchased from Open Biosystems (Huntsville, AL, USA). cDNA encoding human miR-155 was synthesized and cloned into a pBABE retroviral vector (Cell Biolabs, Inc., San Diego, CA, USA). For cell transduction, retroviruses were prepared by transient co-transfection with helper viral vector into HEK293T cells using calcium phosphate precipitation (MACGENE Biotechnology Ltd., Beijing, China). HEK293T cells were transfected with plasmid DNA and cultured at $37^{\circ} \mathrm{C}$ for $6 \mathrm{~h}$, prior to replacement of the medium. At between 36 and $48 \mathrm{~h}$ post-transfection, the supernatant was collected and filtered through a $0.45 \mu \mathrm{m}$ filter. A20 cells were transfected at $\sim 2 \times 10^{6}$ cells/10-cm cell culture dish in DMEM/RMPI-1640 
Table I. Primer sequences used for the amplification of FOXP3 and $\beta$-actin.

\begin{tabular}{llll} 
Gene & Forward primer & Reverse primer & $\begin{array}{l}\text { Product } \\
\text { size, bp }\end{array}$ \\
\hline FOXP3 & 5'-CTCATGATAGTGCCTGTGTCCTCAA-3' & 5'-AGGGCCAGCATAGGTGCAAG-3' & 167 \\
$\beta$-actin & 5'-CATCCGTAAAGACCTCTATGCCAAC-3' & 5'-ATGGAGCCACCGATCCACA-3' & 250 \\
\hline
\end{tabular}

FOXP3 forkhead box P3.

medium (1:1 ratio) supplemented with $8 \mu \mathrm{g} / \mathrm{ml}$ polybrene. After $24 \mathrm{~h}$, the medium was changed to RPMI-1640 medium supplemented with $10 \%$ FBS and $0.05 \mathrm{mM}$ 2-mercaptoethanol prior to culture for further assay. Cell transduction with lentiviral vector encoding shRNA targeting mouse miR-155 was performed according to the manufacturer's protocol (Open Biosystems; GE Healthcare, Chicago, IL, USA). Western blot analysis and RT-qPCR were performed to confirm the knockdown, and A20-miR-155+ and A20-miR-155' subclones were obtained. Total RNA from transfected cells was extracted, and FOXP3 protein expression was determined in A20-miR-155+ and A20-miR-155' cells.

Animals and in vivo tests. The $60 \mathrm{BALB} / \mathrm{c}$ mice were randomly divided into three groups of 20: A20-miR-155', A20-miR- $155^{+}$and the control group. Tumor cells $\left(2 \times 10^{7}\right)$ in $0.2 \mathrm{ml}$ growth medium were subcutaneously injected into the mouse left axillary fossa. Procedures were conducted under sterile conditions. Tumor growth was determined by calculating the tumor volume. Mice were sacrificed when exhibiting external signs of suffering (including decreased mobility and altered behavior). All remaining animals were sacrificed at 30 days. Immediately following excision, the tumor tissues were stored in $10 \%$ neutral-buffered formalin. After $48 \mathrm{~h}$, the samples were paraffin-embedded and then sliced into $4-\mu \mathrm{m}$ sections for hematoxylin and eosin staining. The sections were deparaffinized and rehydrated, followed by antigen retrieval with citrate buffer ( $\mathrm{pH}$ 6.0). Endogenous peroxidase activity was inhibited with $3 \% \mathrm{H}_{2} \mathrm{O}_{2}$ for $15 \mathrm{~min}$ and the sections were incubated with $10 \%$ normal goat serum to block non-specific binding. Following incubation with anti-FOXP3 antibody (dilution, 1:200; cat. no. HPA027342; Santa Cruz Biotechnology, Dallas, TX, USA) at $4^{\circ} \mathrm{C}$ overnight, the sections were washed, treated with biotinylated anti-immunoglobulin antibody (dilution, 1:150; cat. no. LP0012145; Vector Laboratories, Inc., Burlingame, CA, USA) for $20 \mathrm{~min}$ at $25^{\circ} \mathrm{C}$ and reacted with horseradish peroxidase-conjugated streptavidin. A liquid DAB substrate/chromogen system (Fuzhou Maixin Biotech. Co., Ltd., Fuzhou, China) was used, according to the manufacturer's protocol, followed by counterstaining with hematoxylin. Representative images of tumor tissues were captured using a light microscope (Olympus Corporation).

Western blot analysis. A $200 \mathrm{mg}$ sample of tumor tissue was ground with liquid nitrogen using a mortar. A $1 \mathrm{ml}$ volume of protein extraction buffer $(50 \mathrm{mM}$ Tris/ $\mathrm{HCl}, 150 \mathrm{mM} \mathrm{NaCl}$, 0.5 mM EDTA, 1 mM DTT, $1 \%$ Triton X-100, $0.5 \%$ sodium deoxycholate and $0.1 \%$ SDS) with $1 \mathrm{X}$ Halt protease inhibitors
(Pierce; Thermo Fisher Scientific, Inc.) was added. A $1 \mathrm{ml}$ volume of the protein extraction buffer mixture was transferred to a sterile Eppendorf tube and placed in an ice bath at $4^{\circ} \mathrm{C}$ for $20 \mathrm{~min}$ prior to centrifugation at 2,500 $\mathrm{x} \mathrm{g}$. The supernatant was divided into aliquots and stored at $-80^{\circ} \mathrm{C}$. Subsequently, $50 \mu \mathrm{g}$ total cellular protein from each sample was separated by SDS-PAGE (10\% gel) and electrotransferred onto a polyvinylidene fluoride membrane using a semi-dry blotting apparatus (Bio-Rad Laboratories, Inc.). Following blocking for $2 \mathrm{~h}$ at $25^{\circ} \mathrm{C}$ with $5 \%$ skimmed milk, the membranes were hybridized with a mouse monoclonal anti-FOXP3 antibody (dilution, 1:800; cat. no. SAB1402390; Sigma-Aldrich; Merck KGaA) overnight at $4{ }^{\circ} \mathrm{C}$, followed by incubation with secondary antibodies for $8 \mathrm{~h}$ at $4^{\circ} \mathrm{C}$ (dilution, 1:3,000; cat. no. 7072; Cell Signaling Technology, Inc., Danvers, MA, USA). The protein bands were then visualized using Pro-Lighting horseradish peroxidase agent (Cell Signaling Technology, Inc) and their densities were determined using ImageJ software (version 2.1.4.7; imagej. nih.gov/ij). GAPDH (dilution, 1:300; cat. no. SRT1546780; Sigma-Aldrich; Merck KGaA) was used as a loading control.

Cell cycle analysis. Splenic lymphocytes were obtained under sterile conditions following sacrifice of the mice by severing their necks. From each mouse, $100 \mu$ lymphocyte suspension was obtained, to which $4 \mu \mathrm{l}$ anti-cluster of differentiation (CD)4-phycoerthyrin (PE)-cyanine 5.5 (Cy5.5) (dilution, 1:1,500; cat. no. 3324; Cell Signaling Technology, Inc.) and anti-CD25-allophycocyanin (APC) (dilution, 1:1,500; cat. no. 3654; Cell Signaling Technology, Inc.) were each added, followed by aeration and even mixing. The samples were refrigerated at $4^{\circ} \mathrm{C}$ for $30 \mathrm{~min}$. A $1.5 \mathrm{ml}$ volume of precooled flow cytometry staining buffer (cat. no. 00-4222; Cell Signaling Technology, Inc.) was added prior to aeration and stirring to evenly mix the washed cells. Samples were centrifuged at $800 \times \mathrm{g}$ at $4^{\circ} \mathrm{C}$ for $5 \mathrm{~min}$. The supernatant was discarded and cells were resuspended in $1 \mathrm{ml}$ prepared lysis/fixing solution from a PerFix-nc kit (Beckman Coulter, Inc., Brea, CA, USA). Following mixing by vortex, a further $1 \mathrm{ml}$ fixed/ruptured membrane working solution was added and cells were vortex-mixed again. Subsequently, cells were incubated at $4^{\circ} \mathrm{C}$ for $3 \mathrm{~h}$ in darkness. Following incubation, $2 \mathrm{ml}$ prepared ruptured membrane buffer working solution was added prior to aeration and stirring for even mixing with the washed cells. Cells were centrifuged for $800 \mathrm{x}$ g at $8^{\circ} \mathrm{C}$ and the supernatant was discarded. Cells were resuspended in $100 \mu \mathrm{l}$ ruptured membrane working solution and $0.5 \mu \mathrm{g}$ Fc-receptor blocking solution (cat. no. 42232; Cell Signaling Technology, Inc.) was added prior to incubation at $4^{\circ} \mathrm{C}$ for 
Table II. Cox's multivariate analysis of prognosis of diffuse large B-cell lymphoma.

\begin{tabular}{|c|c|c|c|c|c|c|}
\hline \multirow[b]{2}{*}{ Factor } & \multicolumn{3}{|c|}{ OS } & \multicolumn{3}{|c|}{ PFS } \\
\hline & HR & $95 \% \mathrm{CI}$ & P-value & HR & $95 \%$ CI & P-value \\
\hline Age & 1.28 & $0.58-1.34$ & 0.451 & 1.09 & $0.38-2.47$ & 0.623 \\
\hline Metastasis & 0.91 & $0.43-1.92$ & 0.820 & 0.59 & $0.41-1.23$ & 0.701 \\
\hline IPI score & 0.89 & $0.40-1.96$ & 0.779 & 0.62 & $0.33-1.24$ & 0.149 \\
\hline Staging & 1.47 & $0.58-2.36$ & 0.701 & 2.42 & $0.22-2.15$ & 0.494 \\
\hline $\mathrm{FOXP}^{+}$tumor & 2.13 & $1.99-3.42$ & 0.026 & 1.08 & $0.52-1.64$ & 0.348 \\
\hline
\end{tabular}

OS, overall survival; PFS, progression-free survival; HR, hazard ratio; CI, confidence interval; IPI, International Prognostic Index; FOXP3, forkhead box P3.

14 min in the dark. Anti-FOXP3-PE (dilution, 1:500; cat. no. 1716; Cell Signaling Technology, Inc.) or PE-Rat-lgG2a (dilution, 1:500; cat. no., 1285; Cell Signaling Technology, Inc.) was used for homotypic comparison. Following incubation for $14 \mathrm{~min}, 2 \mathrm{ml}$ lysis/fixing solution was added to the washed cells prior to aeration and stirring. Cells were centrifuged at $2,000 \mathrm{x} \mathrm{g}$ at $8^{\circ} \mathrm{C}$ for $30 \mathrm{~min}$. The supernatant was discarded, and cells were resuspended in $500 \mu 10.1 \%$ polyoxymethylene and refrigerated at $4^{\circ} \mathrm{C}$ for $24 \mathrm{~h}$. Samples were examined by flow cytometry using a FACScan cytometer and the results analyzed by ModFitLT software (version 2.0; both from BD Biosciences, Franklin Lakes, NJ, USA).

Statistical analysis. SPSS software (version 20.0; IBM Corp., Armonk, NY, USA) was used for statistical analyses. Data were expressed as the mean \pm standard deviation. Student's t-test for paired samples was performed. $\mathrm{P}<0.05$ was considered to indicate a statistically significant difference.

\section{Results}

Foxp3 expression in distinct cell lines. FOXP3 mRNA expression in normal $\mathrm{B}$ and DLBCL cell lines was examined by RT-qPCR. All 4 cell lines, including normal B and DLBCL cells (Ly1, Ly8 and Ly10), expressed FOXP3 mRNA. Compared with normal B cells, FOXP3 mRNA expression in DLBCL cells (Ly1, Ly8 and Ly10) was significantly increased $(\mathrm{P}<0.05$; Fig. 1).

Foxp3 protein expression in cancer tissues and adjacent tissues. Immunohistochemistry was performed to determine the expression of FOXP3 in DLBCL tumor tissues. The results indicated that the protein expression levels of FOXP3 of cancer tissues were decreased compared with that of adjacent tissues (Fig. 2A-C). By comparing the association between the clinicopathological features of patients with DLBCL, it was identified that increased expression of FOXP3 is a marker of poor prognosis of patients with DLBCL (Table II). Increased expression of FOXP3 in patients with DLBCL was identified to be associated with poor prognosis $(\mathrm{P}<0.05$; Fig. $2 \mathrm{D})$.

Expression of FOXP3 in miR-155-silenced A20 cells. RT-qPCR was used to determine the expression levels of

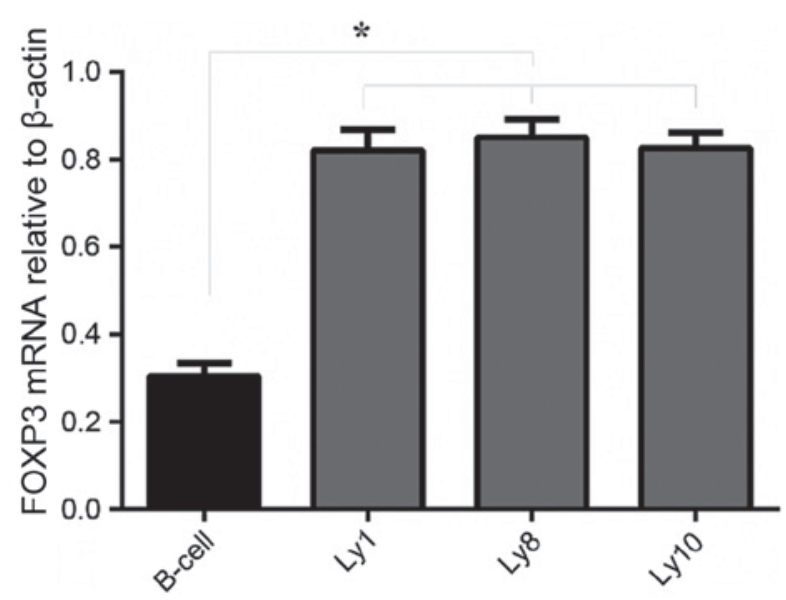

Figure 1. Expression analysis of FOXP3 mRNA in lymphoma cell lines (Ly1, Ly8 and Ly10) and normal B cells using the reverse transcription-quantitative polymerase chain reaction. ${ }^{*} \mathrm{P}<0.05$. FOXP3, forkhead box P3; CT, cycle threshold.

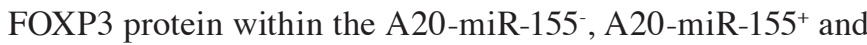
A20 cell lines (Fig. 3A). Silencing miR-155 in A20 cells led to a significant decrease in the expression of FOXP3 protein $(\mathrm{P}<0.05$; Fig. 3B).

Histology of tumors in BALB/c mice. Subcutaneous tumor models were successfully established in BALB/c mice. Tumor growth of the mice injected with A20-miR-155+ cells was increased compared with the A20-miR-155- group (Table III). At 30 days after injection of A20 cells, the mice with silenced miR-155 demonstrated a decreased tumor volume (Fig. 4A). Visible tumors were round or oval with nodules and were adherent to the surface of the skin of the capillary-rich gray cut surface, with no distant lymph node metastasis. Microscopic imaging of the tumor tissue demonstrated that the tumor cells exhibited diffuse homogeneous infiltrates consisting of large and cohesive tumor cells with moderate cytoplasm and pleomorphic nuclei (Fig. 4B). Occasionally pathological mitotic figures and a limited number of small lymphocytes were observed. Western blot analysis was used to determine the protein expression level of FOXP3, which was increased in A20-miR- $155^{+}$cells (Fig. 4C). 


\section{A}

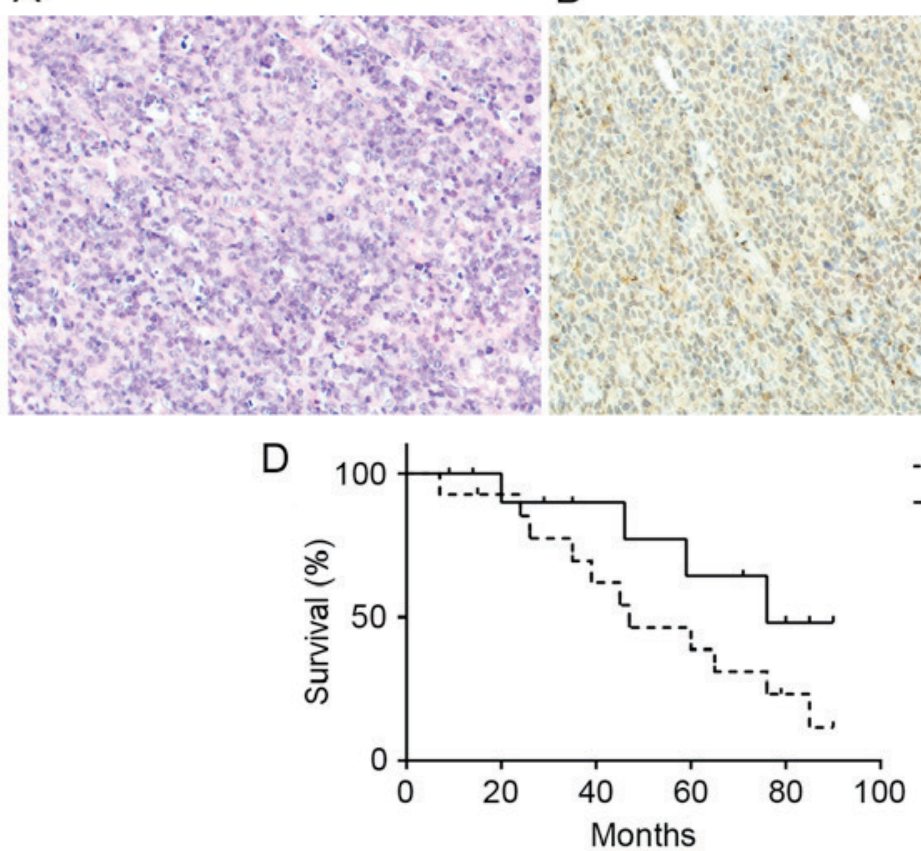

C

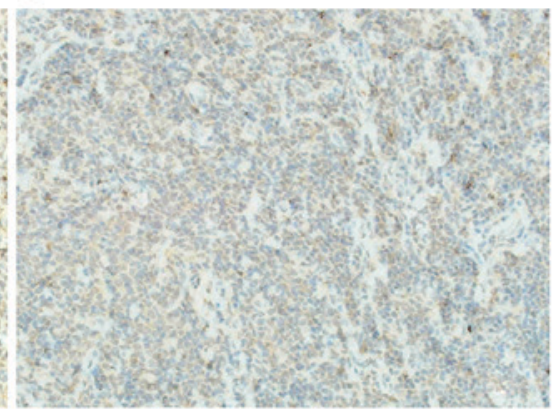

-..FOXP3 high expression

- FOXP3 low expression

Figure 2. Representative images of immunohistochemical analysis of the expression patterns of FOXP3 in different tumors. Magnification, $\mathrm{x} 200$. (A) Hematoxylin and eosin staining in tumor tissues of patients with DLBCL. (B) Expression of FOXP3 in tumor tissues of patients with DLBCL. (C) Expression of FOXP3 in adjacent tissues of patients with DLBCL. (D) The increased expression of FOXP3 is a factor associated with poor prognosis of patients with DLBCL. DLBCL, diffuse large B-cell lymphoma; FOXP3, forkhead box P3.

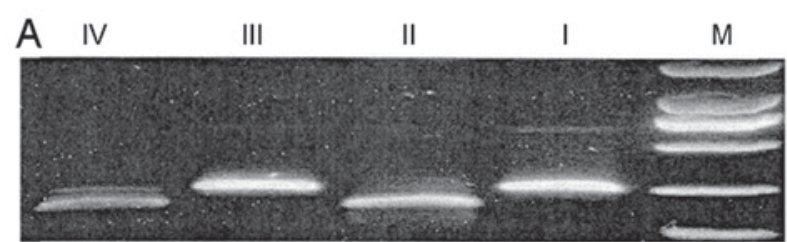

B

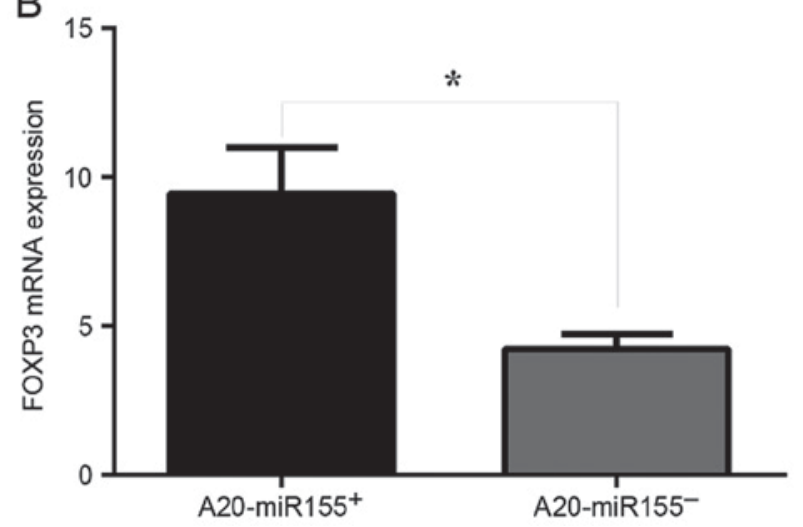

Figure 3. Expression of FOXP3 is deceased in miR-155-silenced A20 cells. (A) RT-qPCR analysis of FOXP3 expression. Lane M, marker; lanes I and III, controls; lane II, A20-miR-155+ cells; lane IV, A20-miR-155 cells. (B) Quantification of RT-qPCR. *P<0.05. FOXP3, forkhead box P3; miR-155, microRNA-155; RT-qPCR, reverse transcription-quantitative polymerase chain reaction.

Flow cytometric analysis of $\mathrm{CD}^{+} \mathrm{CD} 25^{+} \mathrm{FOXP} 3^{+} \mathrm{T}$ cells. The proportion of $\mathrm{CD} 25^{+} \mathrm{FOXP} 3^{+} \mathrm{T}$ cells to total $\mathrm{CD} 4^{+}$ $\mathrm{T}$ cells was determined using flow cytometry in each group and was identified to be significantly increased in A20-miR-155+-transducted mice compared with the other groups ( $\mathrm{P}<0.05$; Fig. 4D).
Table III. Tumor growth of mice following injection of A20 cells.

\begin{tabular}{lcccc}
\hline Group & $\mathrm{n}(\%)$ & $\begin{array}{c}\text { Time, } \\
\text { days }\end{array}$ & $\begin{array}{c}\text { Weight, } \\
\mathrm{g}\end{array}$ & $\begin{array}{c}\text { Volume, } \\
\mathrm{mm}^{3}\end{array}$ \\
\hline A20-miR-155 & $\begin{array}{c}19 / 20 \\
(95)\end{array}$ & $7.0 \pm 0.9$ & $2.11 \pm 0.42$ & $1612 \pm 191.94^{\mathrm{a}}$ \\
A20-miR-155 & $\begin{array}{c}12 / 20 \\
(60.0)\end{array}$ & $9.5 \pm 2.8$ & $1.12 \pm 0.14$ & $998.00 \pm 99.85^{\mathrm{a}, \mathrm{b}}$ \\
A20 & $\begin{array}{c}14 / 20 \\
(70)\end{array}$ & $9.0 \pm 1.8$ & $1.67 \pm 0.22$ & $1367 \pm 139.25^{\mathrm{b}}$ \\
& & & & \\
\hline
\end{tabular}

${ }^{\mathrm{a}} \mathrm{P}<0.01 ;{ }^{\mathrm{b}} \mathrm{P}=0.729$.

\section{Discussion}

The results of the present study identified that: Under the same conditions, the expression of FOXP3 in human DLBCL cell lines (Ly1, Ly8 and Ly10) was increased compared with in Bcells. By comparing the expression quantity of FOXP3 in the DLBCL tumor tissue samples and tissue samples adjacent to tissues, it was identified that the expression of FOXP3 in the former was increased compared with that in the latter. The analysis of the clinical data revealed that the increased expression of FOXP3 is one of the factors indicating poor prognosis of DLBCL. This may because of an immunosuppressive function of FOXP $3^{+} \mathrm{T}$ cells. T cells participated in the immunoevasion of certain tumors and promoted the generation and development of tumors by assisting in the monitoring of the immunoevasion system of the tumor cells (18). CD $4{ }^{+} \mathrm{CD} 25^{+}$ 
A

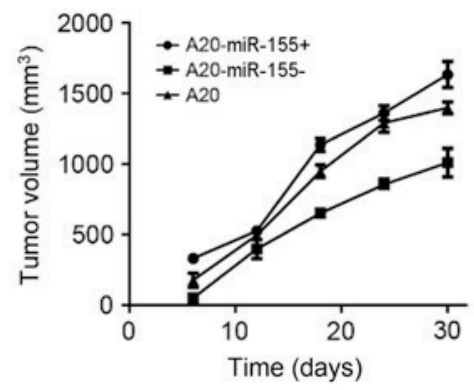

B
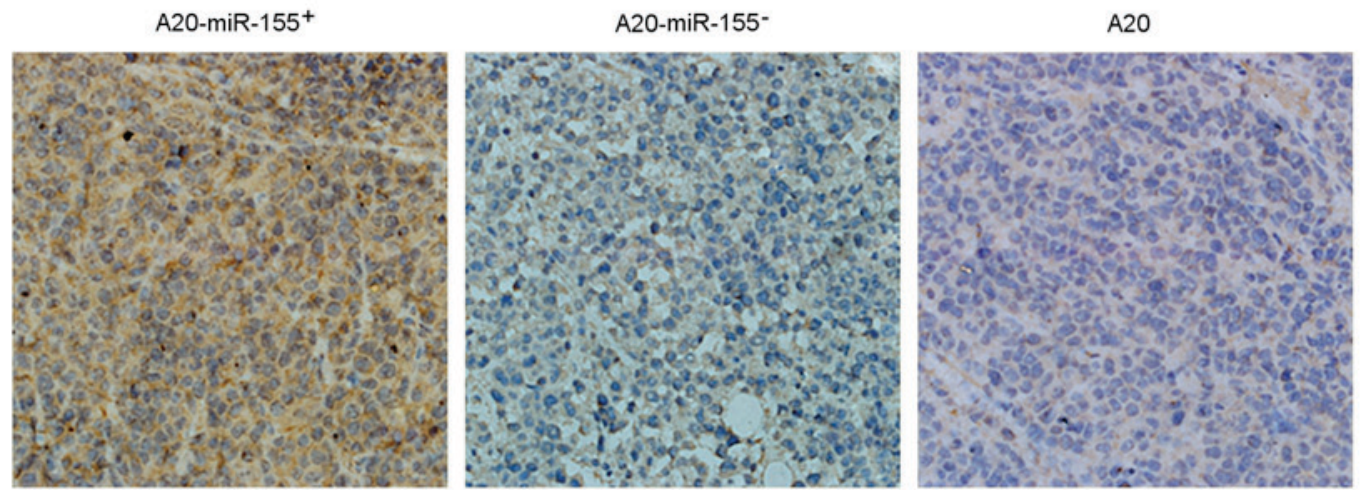

C

A20-miR-155+ A20-miR-155- A20
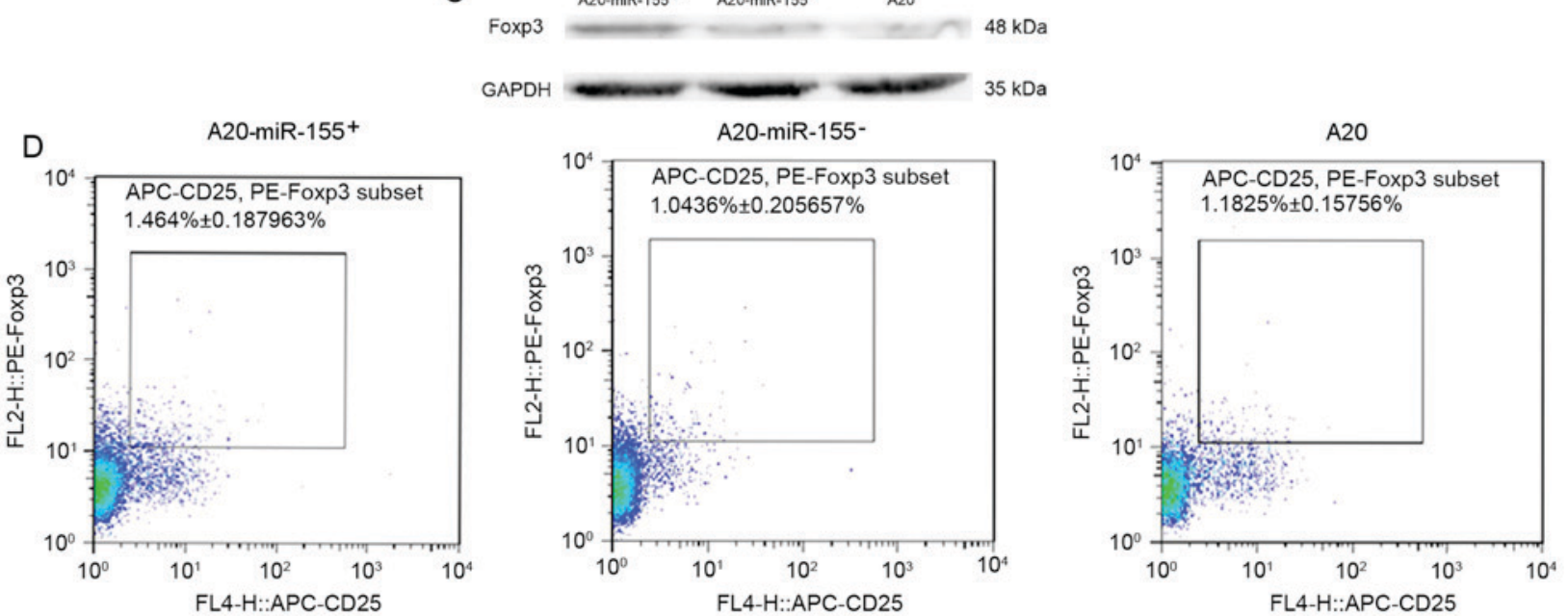

Figure 4. The effect of A20 cell line variant injection into mice. (A) Tumor formation is increased in A20-miR-155+-transducted mice compared with A20-miR-155- and A20-transducted mice. (B) Immunohistochemical analysis of tumor tissues of A20-miR-155+-, A20-miR-155- and A20-transducted mice. (C) Western blot analysis of FOXP3 protein expression in tumor tissues of mice identified that increased FOXP3 expression in A20-miR-155 -transducted mice compared with A20-miR-155- and A20-transducted mice. GAPDH was used as a loading control. (D) Flow cytometric analysis of $\mathrm{CD} 4^{+} \mathrm{CD} 25^{+} \mathrm{FOXP} 3^{+} \mathrm{T}-\mathrm{cells}$. The proportion of the FOXP3 ${ }^{+} \mathrm{T}$ cells in the A20-miR-155-transducted mice was the least among the groups, whereas that in the A20-miR-155'-transducted mice was significantly increased compared with A20-miR-155-transducted mice ( $\mathrm{P}<0.05)$. miR-155, microRNA-155; FOXP3, forkhead box P3; CD, cluster of differentiation; PE, phycoerythrin; APC, allophycocyanin.

T cells are an important $\mathrm{CD} 4^{+}$Treg lymphocyte subpopulation in the immune microenvironment, which serve an important role in maintaining the self-stability of the immune system and preventing autoimmune diseases $(20,21)$. As an indicator of the specificity of the $\mathrm{CD} 4{ }^{+} \mathrm{CD} 25^{+} \mathrm{T}$ cells, FOXP3 is a major regulatory factor that stimulates the development of $\mathrm{CD} 4^{+} \mathrm{CD} 25^{+}$ $\mathrm{T}$ cells and the biological function, and may decrease the immune response. Previous studies have demonstrated that the proportion of T cells within the lymphocytes that had infiltrated the tumor tissues of patients with lung cancer, gastric cancer and ovarian cancer is high and is associated with the poor prognosis of patients $(22,23)$. However, it has been identified that the increased level of FOXP3 protein expression within follicular lymphoma and skin T cell lymphoma is a predictor of good prognosis $(9,10)$. Furthermore, a previous study examined the absolute value of FOXP3 ${ }^{+} \mathrm{T}$ cells in 1,019 cases of distinct types of lymphoma tissues and analyzed the association between its expression level and the prognosis (24). This study demonstrated that patients with DLBCL, follicular lymphoma and classic Hodgkin's lymphoma may exhibit long survival times if the number of $\mathrm{FOXP}^{+} \mathrm{T}$ cells increases. However, among the patients with DLBCL in the middle and late stage, the increase in FOXP $3^{+} \mathrm{T}$ cells is associated with poor prognosis (24). Previous studies have demonstrated that FOXP3 ${ }^{+}$ Tregs exist in tumor tissue mesenchyme and that FOXP3 is expressed in various tumor cells (including pancreatic, breast, 
malignant melanin and gastric cancer) (25-27). These studies identified that FOXP3 is expressed in DLBCL tumor cells and that the number of $\mathrm{FOXP}^{+} \mathrm{T}$ cells within the tumors is significantly positively associated with overall survival and provide a solid basis for the study of the effect of inhibiting the expression of FOXP3 on DLBCL.

miR-155 is located within the third exon (21q21.3) of the B-cell integration cluster (BIC) on human chromosome 21. The gene does not include the open reading frame, so the expression level is regulated and controlled by the BIC transcriptional level and the processing of miRNA (28). It promotes the abnormal proliferation of cells through its expression and serves an important role in cancer. The copy number of miR-155 within tumor cells of DLBCL is between 10- and 30-fold that of normal $\mathrm{B}$ cells, and its expression in the plasma of patients with DLBCL is increased 5.24-fold compared with healthy individuals (28). The expression level in the activated B cell phenotype of DLBCL is increased between 2- and 3-fold compared with that of the germinal center phenotype of DLBCL (29). Therefore, an association between miR-155 and DLBCL has been identified. However, the results of the present study suggested that, following silencing of the expression of miR-155 in the DLBCL cell line A20, the expression level of FOXP3 within the A20 cell line is decreased accordingly. In the mouse experiment, the tumorigenicity rate and time of the A20-miR-155-transducted mice were significantly decreased compared with those of the A20-miR-155+-transducted mice. Using immunohistochemical analysis of the expression of FOXP3 in the tumor tissues of mice, it was identified that the expression of FOXP3 within the tumor tissues of A20-miR-155'-transducted mice was decreased markedly when compared with that of A20-miR-155-transducted mice. The subsequent flow cytometry experiment also demonstrated that the number of $\mathrm{T}$ cells within lymphocytes of A20-miR-155'-transducted mice decreased compared with A20-miR-155-transducted mice. These results suggested that miR-155 may be a promoter of FOXP3, but the underlying molecular mechanism remains unclear. A previous study suggested that the increased expression of miR-155 in T cells promotes the proliferation of $\mathrm{T}$ cells (30). In mice lacking miR-155, the number of $\mathrm{T}$ cells within their spleen and thymus was significantly decreased; however, it was indicated that the suppressive effect of Tregs that lack miR-155 was the same as normal Tregs (31). It was also demonstrated that the underlying molecular mechanism for how miR-155 adjusts the proliferation of T cells may involve the interleukin (IL)-2 signaling pathway (32). A previous study has demonstrated the vital role of IL-2 in maintaining the dynamic balance of T cells (31). However, suppressor of cytokine signaling 1 (SOCS1; the negative regulatory factor in the IL-2 signaling pathway) is a direct target gene of miR-155. The lack of miR-155 can result in the increased expression of SOCS1, thus inhibiting the phosphorylation of signal transducer and activator of transcription 5 , resulting in damage to the IL-2 signaling pathway and finally decreasing the proliferative capacity of T cells (29). A previous study has suggested that miR-155 promotes the proliferation of $\mathrm{T}$ cells and Th17 cells through negative regulation of SOCS1 and induces Th17cells to secrete IL-17, but is unable to stimulate $\mathrm{T}$ cells to secrete IL-10 and transforming growth factor $\beta$ (33), also demonstrating the influence of miR-155 on T cells and their specific marker, FOXP3.
In the present study, RT-qPCR was used to determine the FOXP3 mRNA expression level within human DLBCL cell lines and normal B cells. Immunohistochemical analysis was performed to determine the expression of FOXP3 in tumor tissues and surrounding tumors. The association between the expression of FOXP3 in tumor organization and the prognosis of patients with DLBCL was analyzed. The results indicated that FOXP3 is an indicator of poor prognosis of patients with DLBCL in the middle and late stage. It was also identified that, following silencing of miR-155 in the A20 cell line, the FOXP3 expression level also decreased. In the studies using mice, the tumorigenicity of mice transfected with A20-miR-155 was decreased compared with those transfected with A20-miR-155'. The number of FOXP3 and T cells exhibited the same trend. It may be that miR-155 is an upstream factor of FOXP3. This potential underlying molecular mechanism provides the experimental basis for the inhibition of the expression of T cells and their specificity marker, FOXP3, and the treatment of DLBCL via targeting FOXP3.

\section{Acknowledgements}

The present study was supported by the Natural Science Foundation of Zhejiang Province (grant no. LY15H160049).

\section{References}

1. Cultrera JL and Dalia SM: Diffuse large B-cell lymphoma: Current strategies and future directions. Cancer Control 19: 204-213, 2012.

2. Campbell DJ and Ziegler SF: FOXP3 modifies the phenotypic and functional properties of regulatory T cells. Nat Rev Immunol 7: 305-310, 2007.

3. Xu CT, Li WM and Yao YM: Regulating mechanism of regulatory $\mathrm{T}$ cells in immunoregulatory responses. Int $\mathrm{J}$ Pathol Clin Med 28: 0199-0106, 2008.

4. Schwartz RH: Natural regulatory T cells and self-tolerance. Nat Immunol 6: 327-330, 2005.

5. Curiel TJ: Tregs and rethinking cancer immunotherapy. J Clin Invest 117: 1167-1174, 2007.

6. Sakaguchi S, Miyara M, Costantino CM and Hafler DA: FOXP3 ${ }^{+}$ regulatory $\mathrm{T}$ cells in the human immune system. Nat Rev Immunol 10: 490-500, 2010.

7. Kryczek I, Liu R, Wang G, Wu K, Shu X, Szeliga W, Vatan L, Finlayson E, Huang E, Simeone D, et al: FOXP3 defines regulatory T cells in human tumor and autoimmune disease. Cancer Res 69: 3995-4000, 2009.

8. Fontenot JD, Rasmussen JP, Williams LM, Dooley JL, Farr AG and Rudensky AY: Regulatory T cell lineage specification by the forkhead transcription factor foxp3. Immunity 22: 329-341, 2005.

9. Karanikas V, Speletas M, Zamanakou M, Kalala F, Loules G, Kerenidi T, Barda AK, Gourgoulianis KI and Germenis AE: FOXP3 expression in human cancer cells. J Transl Med 6: 19, 2008.

10. Generali D, Bates G, Berruti A, Brizzi MP, Campo L, Bonardi S, Bersiga A, Allevi G, Milani M, Aguggini S, et al: Immunomodulation of $\mathrm{FOXP}^{+}$regulatory $\mathrm{T}$ cells by the aromatase inhibitor letrozole in breast cancer patients. Clin Cancer Res 15: 1046-1051, 2009.

11. Tzankov A, Meier C, Hirschmann P, Went P, Pileri SA and Dirnhofer S: Correlation of high numbers of intratumoral $\mathrm{FOXP}^{+}$regulatory $\mathrm{T}$ cells with improved survival in germinal center-like diffuse large B-cell lymphoma, follicular lymphoma and classical Hodgkin's lymphoma. Haematologica 93: 193-200, 2008.

12. Calin GA and Croce CM: MicroRNA signatures in human cancers. Nat Rev Cancer 6: 857-866, 2006.

13. Cobb BS, Hertweck A, Smith J, O'Connor E, Graf D, Cook T, Smale ST, Sakaguchi S, Livesey FJ, Fisher AG and Merkenschlager M: A role for Dicer in immune regulation. J Exp Med 203: 2519-2527, 2006. 
14. Seo KH, Zhou L, Meng D, Xu J, Dong Z and Mi QS: Loss of microRNAs in thymus perturbs invariant NKT cell development and function. Cell Mol Immunol 7: 447-453, 2010.

15. Sadlon TJ, Wilkinson BG, Pederson S, Brown CY, Bresatz S, Gargett T, Melville EL, Peng K, D'Andrea RJ, Glonek GG, et al: Genome-wide identification of human FOXP3 target genes in natural regulatory T cells. J Immunol 185: 1071-1081, 2010.

16. Yamamoto M, Kondo E, Takeuchi M, Harashima A, Otani T, Tsuji-Takayama K, Yamasaki F, Kumon H, Kibata M and Nakamura S: miR-155, a modulator of FOXO3a protein expression, is underexpressed and cannot be upregulated by stimulation of HOZOT, a line of multifunctional Treg. PLoS One 6: e16841, 2011.

17. National Research Council: Guide for the Care and Use of Laboratory Animals. National Academies Press, Washington, DC, pp41-48, 1974

18. Mestdagh P, Van Vlierberghe P, De Weer A, Muth D, Westermann F, Speleman F and Vandesompele J: A novel and universal method for microRNA RT-qPCR data normalization. Genome Biol 10: R64, 2009.

19. Kraan MC, Smith MD, Weedon H, Ahern MJ, Breedveld FC and Tak PP: Measurement of cytokine and adhesion molecule expression in synovial tissue by digital image analysis. Ann Rheum Dis 60: 296-298, 2001.

20. Shiozawa E, Yamochi-Onizuka T, Takimoto M and Ota H: The GCB subtype of diffuse large B-cell lymphoma is less frequent in Asian countries. Leuk Res 31: 1579-1583, 2007.

21. Oki Y, Yamamoto K, Kato H, Kuwatsuka Y, Taji H, Kagami Y and Morishima Y: Low absolute lymphocyte count is a poor prognostic marker in patients with diffuse large B-cell lymphoma and suggests patients' survival benefit from rituximab. Eur J Haematol 81: 448-453, 2008.

22. Jabłońska J, Jesionek-Kupnicka D, Potemski P, Kowalik A, Sygut J and Kordek R: Comparison of two different immunohistochemical algorithms identifying prognostic subgroups of DLBCL. Pol J Pathol 61: 124-132, 2010.

23. Qian BZ and Pollard JW: Macrophage diversity enhances tumor progression and metastasis. Cell 141: 39-51, 2010.

24. Kono K, Kawaida H, Takahashi A, Sugai H, Mimura K, Miyagawa N, Omata $\mathrm{H}$ and Fujii $\mathrm{H}$ : CD4(+)CD25high regulatory $\mathrm{T}$ cells increase with tumor stage in patients with gastric and esophageal cancers. Cancer Immunol Immunother 55: 1064-1071, 2006.
25. Badoual C, Hans S, Rodriguez J, Peyrard S, Klein C, Agueznay Nel H, Mosseri V, Laccourreye O, Bruneval P, Fridman WH, et al: Prognostic value of tumor-infiltrating $\mathrm{CD} 4^{+} \mathrm{T}$-cell subpopulations in head and neck cancers. Clin Cancer Res 12: 465-472, 2006.

26. Salama P, Phillips M, Grieu F, Morris M, Zeps N, Joseph D, Platell $\mathrm{C}$ and Iacopetta B: Tumor-infiltrating FOXP $3^{+} \mathrm{T}$ regulatory cells show strong prognostic significance in colorectal cancer. J Clin Oncol 27: 186-192, 2009.

27. Khattri R, Cox T, Yasayko SA and Ramsdell F: An essential role for Scurfin in $\mathrm{CD} 4^{+} \mathrm{CD} 25^{+} \mathrm{T}$ regulatory cells. Nat Immunol 4: 337-342, 2003.

28. Rai D, Karanti S, Jung I, Dahia PL and Aguiar RC: Coordinated expression of microRNA-155 and predicted target genes in diffuse large B-cell lymphoma. Cancer Genet Cytogenet 181: $8-15,2008$

29. Eis PS, Tam W, Sun L, Chadburn A, Li Z, Gomez MF, Lund E and Dahlberg JE: Accumulation of miR-155 and BIC RNA in human B cell lymphomas. Proc Natl Acad Sci USA 102: 3627-3632, 2005.

30. Kohlhaas S, Garden OA, Scudamore C, Turner M, Okkenhaug K and Vigorito E: Cutting edge: The Foxp3 target miR-155 contributes to the development of regulatory T cells. J Immunol 182: 2578-2582, 2009

31. Bayer AL, Yu A and Malek TR: Function of the IL-2R for thymic and peripheral $\mathrm{CD} 4{ }^{+} \mathrm{CD} 25^{+} \mathrm{Foxp} 3^{+} \mathrm{T}$ regulatory cells. J Immunol 178: 4062-4071, 2007.

32. Lu LF, Thai TH, Calado DP, Chaudhry A, Kubo M, Tanaka K, Loeb GB, Lee H, Yoshimura A, Rajewsky K and Rudensky AY: Foxp3-dependent microR-NA155 confers competitive fitness to regulatory $\mathrm{T}$ cells by targeting SOCS1. Immunity 30: 80-91, 2009.

33. Yao R, Ma YL, Liang W, Li HH, Ma ZJ, Yu X and Liao YH: MicroRNA-155 modulates Treg and Th17 cells differentiation and Th17 cell function by targeting SOCS1. PLoS One 7: e46082, 2012. 